\title{
Conservation ecology of rare plants within complex local habitat networks
}

\author{
Benjamin J. Crain, Ana María Sánchez-Cuervo, Jeffrey W. White \\ and STEVEN J. S TEINBERG
}

\begin{abstract}
Effective conservation of rare plant species requires a detailed understanding of their unique distributions and habitat requirements to identify conservation targets. Research suggests that local conservation efforts may be one of the best means for accomplishing this task. We conducted a geographical analysis of the local distributions of rare plants in Napa County, California, to identify spatial relationships with individual habitat types. We measured the potential contribution of individual habitats to rare plant conservation by integrating analyses on overall diversity, species per area, specificity-weighted richness, presence of hotspots, and the composition of the rare plant community in each habitat type. This combination of analyses allowed us to determine which habitats are most significant for rare plant conservation at a local scale. Our analyses indicated that several habitat types were consistently associated with rare plant species. In broad terms, grasslands, oak forests, coniferous forests, wetlands, serpentines, chaparral, and rock outcrops were most consistently highlighted. No single habitat stood out in every analysis however, and therefore we conclude that careful selection of an assemblage of habitats that best represents diverse, restricted and unique rare plant communities will be the most efficient approach to protecting rare plant habitat at local scales. Accordingly we present a means of identifying conservation targets and protecting global biodiversity through local efforts.
\end{abstract}

Keywords California, conservation targets, environmental planning, geographical distributions, habitat conservation, Napa County, species-area models, threatened species

This paper contains supplementary material that can be found online at http://journals.cambridge.org

Benjamin J. Crain (Corresponding author) and JefrRey W. White Department of Biological Sciences, Humboldt State University, 1 Harpst Street, Arcata, CA, 95521, USA. E-mail bcrainium@yahoo.com

Ana María SÁnchez-Cuervo Department of Biology, University of Puerto Rico -Río Piedras, San Juan, Puerto Rico

SteVen J. Steinberg Department of Environmental Science and Management, Humboldt State University, Arcata, USA

Received 19 June 2013. Revision requested 6 August 2013.

Accepted 4 September 2013. First published online 24 February 2014.

\section{Introduction}

Dlant taxa dominate lists of rare and threatened species 1 and should be prioritized for conservation (Dixon \& Cook, 1989; Campbell, 1991; Ellstrand \& Elam, 1993; Sharrock, 2011). Habitat specificity is often used as a primary criterion for classifying rare species (Rabinowitz, 1981) and a detailed understanding of the distribution and habitats of rare plants is critical for proactive conservation planning and for identifying areas of interest for preservation (Griggs, 1940; Wiser et al., 1998; Wu \& Smeins, 2000; Peterson, 2006; Fiedler et al., 2007). The first stage of systematic conservation planning, which is a structured framework for identifying and maintaining priority areas for biodiversity preservation, prioritizes the compilation of distribution data for rare and threatened species as they are usually underrepresented when establishing new protected areas (Margules \& Pressey, 2000). Some countries (e.g. USA, Mexico, Colombia, Italy, Spain and France) have initiated broad conservation strategies that focus on the preservation of rare plants and their habitats at national scales (Planta Europa, 2003; CONABIO, 2008; García et al., 2010; CNHP, 2011; Sharrock, 2011). These large-scale conservation strategies are important for raising public awareness and prompting political action but smaller scale studies are also needed for local conservation practitioners.

The scale at which geographical analyses are conducted is an important consideration for conservation biologists and government stakeholders (Abbitt et al., 2000; Wu \& Smeins, 2000). Although global efforts are valuable for providing general focus and support (Myers, 2003), studies have found that rare plants often occur in small patches of habitat that are manageable at local scales (Kelly \& Fletcher, 1994; Gillespie, 2005; Safford et al., 2005; Fiedler et al., 2007) and therefore county, municipality or parishlevel conservation managers may be able to preserve them (Press et al., 1996; Wiser et al., 1998). With information on the distributions and habitat requirements of rare plants, local governments, researchers and private stakeholders can acquire, regulate and manage land to sustain existing populations and to facilitate range expansion or migration (Press et al., 1996; Fiedler et al., 2007; Kelly \& Goulden, 2008). Consequently, documenting the local distribution of rare plants and their key vegetation associations provides an opportunity for local conservation planners to influence biodiversity globally. 


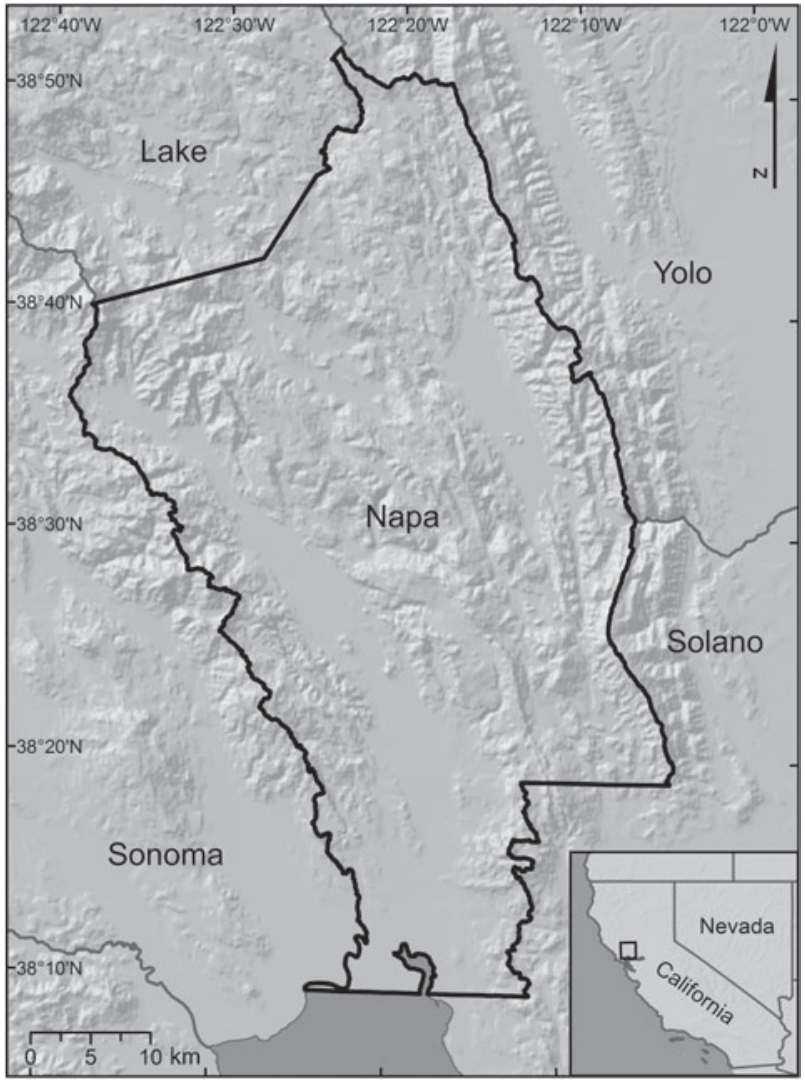

Fig. 1 Napa County, California. The rectangle on the inset shows the location of the main map in California.

For these reasons our overall objective was to combine data on rare plant distribution and land cover (i.e. habitat types) to decipher which habitats are most important for local conservation of rare plant diversity. We had five specific aims: (1) determine which types of habitat rare plants occupy, to identify important habitats at a local scale, (2) determine if hotspots of rare plant richness correspond with particular habitat types, (3) determine if rare plants show signs of habitat specificity at a local scale, (4) determine if habitat-specific species correspond with particular habitat types, and (5) analyse the composition of rare plant communities in different habitat types to identify assemblages of habitats that would jointly support the greatest level of diversity. Our methodology is intended to demonstrate how local management groups can highlight specific habitats that merit special attention in conservation and land-acquisition plans.

\section{Study area}

This analysis was conducted in Napa County, California (Fig. 1), which constitutes an important biological component of the California Floristic Province (Skinner \& Pavlik, 1994; Chaplin et al., 2000; Parisi, 2003). The floristic diversity of Napa County is unique (Major, 1963; Neilson
\& McQuaid, 1981; Crain \& White, 2013) and a disproportionately large number of rare and endemic plants exist there (Stebbins \& Major, 1965; Parisi, 2003; Crain \& White, 2011, 2013; CNDDB, 2013a,b) and consequently Napa County is an ideal study area for testing methods aimed at protecting global plant diversity within a local jurisdiction. The distributions of many of these plant species have been documented by geographical analyses (CNDDB, 2006; Viers et al., 2006; Crain et al., 2011).

\section{Methods}

To determine the extent of overlap between the local distribution of rare plants and land-cover types (i.e. habitat types) we overlaid two geographical data layers comprising multiple polygons. The first layer consisted of polygons showing the distribution of 55 rare plants in Napa County (Supplementary Table 1); i.e. plants categorized as critically imperilled, imperilled, or vulnerable to extirpation at global or state levels according to criteria outlined by NatureServe (CNDDB, 2006). These species have restricted distributions or low population numbers or they are experiencing steep declines (Bittman, 2001; Master et al., 2009). The second polygon layer was a high-resolution land-cover map of Napa County (Thorne et al., 2004; Supplementary Table 2). We excluded human-dominated land use (e.g. urban and agriculture) because our analysis focused on conservation of natural habitats.

Using the spatial join tool in the geographical information system (GIS) ArcGIS v. 9.3.1 (ESRI, Redlands, USA) we were able to overlay and fuse these two geographical layers and subsequently identify correspondence between the distribution of rare plants and the various habitats in Napa County. To produce a rare-plant richness or hotspots layer the distributions of individual rare species (CNDDB, 2006) were coded for presence and absence, overlaid and summed. The resulting layer showed polygons coded for the number of rare plants within them. The richest $5 \%$ of the polygons occupied by multiple rare plants were considered hotspots. Lastly we used the spatial join tool to create a spatially explicit layer that identified the habitat type(s) in which each hotspot occurred.

To identify important habitats in Napa County we used data from our initial spatial join to calculate the number of rare plant species per habitat type. We also calculated the percentage of each habitat type that was occupied by rare plants. The tendency for larger patches of habitat to contain greater numbers of species is well established (Connor \& McCoy, 2001), therefore to identify important habitats, accounting for the differences in the overall area covered by each habitat type, we generated a species-richness-area model with log transformed data and the linear form of the power function (Veech, 2000). Following established 
protocols (Pomeroy, 1993; Ceballos \& Brown, 1995; Estill \& Cruzan, 2001) we identified points that were furthest from the expected species richness values predicted by the model to identify habitat types that supported a greater or lesser number of rare species than would be expected because of the effects of area alone.

To determine if hotspots of rare plant richness correspond with particular habitat types we calculated the overall area of rare plant hotspots within each habitat type. Next, we calculated the percentage of each habitat type that was occupied by hotspots to account for the differences in the overall area covered by each habitat type. This process allowed us to determine if habitat types occupied by hotspots were distinct from those occupied by individual rare plants.

To determine if individual rare plant species were restricted to a few habitat types, as noted by Press et al. (1996) for example, or if they were more cosmopolitan, we calculated the number of habitats in which each rare plant occurred. We used these data to create a frequency histogram of the number of occupied habitats per species. We calculated the skewness of the histogram as the third central moment $\left(g_{1}\right)$ of the distribution and the significance of the skewness statistic was tested using a two-tailed $t$-test (Estill \& Cruzan, 2001; Sokal \& Rohlf, 2012). Positive values of $g_{1}$ signify right-skewed data or a tendency for species to occupy a small number of habitat types, negative $g_{1}$ values indicate that species generally occupy several habitat types, and a value of zero would suggest no skew in the data.

To assess which habitat types were associated with high richness levels, considering habitat specificity, we calculated a specificity-weighted richness index for each habitat type, using methods similar to those outlined by Estill \& Cruzan (2001). We calculated a habitat specificity value for each rare plant species by taking the inverse of the number of habitat types in which it occurred. We then summed the habitat specificity values of the species occurring within each habitat type:

$$
S W R I_{\text {habitat type }}=\sum_{i=1}^{n} \frac{1}{v_{i}}
$$

where $v_{i}$ is the number of habitat types that species $i$ occurs in and $n$ is the number of rare species within the habitat type. This analysis enabled us to identify habitats that supported a diversity of rare plants while giving weight to specialized species.

To detect differences in the composition of rare species among habitat types we performed a non-metric multidimensional scaling ordination analysis. We developed a main matrix containing data on the presence or absence of rare species per habitat. We selected a Jaccard distance measure and the autopilot mode in PC-Ord v. 5.o (McCune $\&$ Mefford, 2002) to find the dimension of our data (we used a step down in dimensionality). The final analysis included 50 runs with real data, stability criterion $=0.00001,200$ iterations to assess stability, 250 maximum iterations, initial step length $=0.20$, and random starting coordinates. The percentage correlation with the distance matrix $(r)$ was calculated to evaluate the efficiency of the ordination distance. With this analysis we elucidated which habitats were the most unique in terms of rare plant composition, allowing us to identify those that could collectively support the greatest overall diversity of rare plants in Napa County.

\section{Results}

The rare plants of Napa County overlapped with 50 local habitat types (Supplementary Table 2). The mean number of species per habitat was $15.64 \pm$ SD 8.55 . Overall, California Annual Grasslands (3) had the greatest number of rare plant species $(n=40)$, Upland Annual Grasslands (14) had the second highest number $(\mathrm{n}=33)$ and Mixed Oak (6) ranked third $(n=30)$. There were 27 rare plant species in each of Blue Oak (2) and Chamise (4). An additional 12 habitat types had $>20$ rare species and 17 habitat types had $\geqslant 10$ rare species. Only five habitat types were not occupied by rare species: Sparse California Juniper Steep Rock Outcrops (44), Coyote Brush (55), Lotus scoparius (56), Sparse Bush Lupine Rock Outcrops (57), and California Juniper (59). The majority of habitat types in Napa County were occupied by at least one rare species (Supplementary Table 2).

The percentage of each habitat type that was occupied by rare plant species indicated the probability of a rare plant occupying that particular habitat (Supplementary Table 2). The mean percentage occupied was $17.26 \pm$ SD $16.03 \%$ of a given habitat. Overall, Sugar Pine/Canyon Oak (58) had the largest percentage occupied by rare plants (100\%). Ponderosa Pine (53) and Douglas-fir/Ponderosa Pine (16) were occupied by rare plants in c. 50\% of their ranges and Canyon Live Oak (40) and Tanbark Oak (51) corresponded with rare plants in c. $35 \%$ of their ranges. Conversely, Chamise/Wedgeleaf Ceanothus (20), Interior Live Oak/ Foothill Pine (11), Interior Live Oak (23), Scrub Interior Live Oak Mesic (15), and Sargent Cypress (32) were all occupied by rare plants in $<5 \%$ of their overall range.

The percentage of the land area of Napa County occupied by each habitat type also varied greatly (Thorne et al., 2004; Supplementary Table 2) and presumably affected the overall number of rare plant species that occupied a given habitat. The species-area model showed that species richness was positively correlated with the area occupied by individual habitat types $\left(r^{2}=0.67 ; \mathrm{P}<0.01\right.$; Fig. 2). Five habitat types had richness values furthest above the values predicted by the model: Carex spp./Wet Meadow (48), Rock Outcrops (35), Brewer's Willow (52), Mixed Willow (42), and Bulrush/Cattail (49). Conversely, Coast 


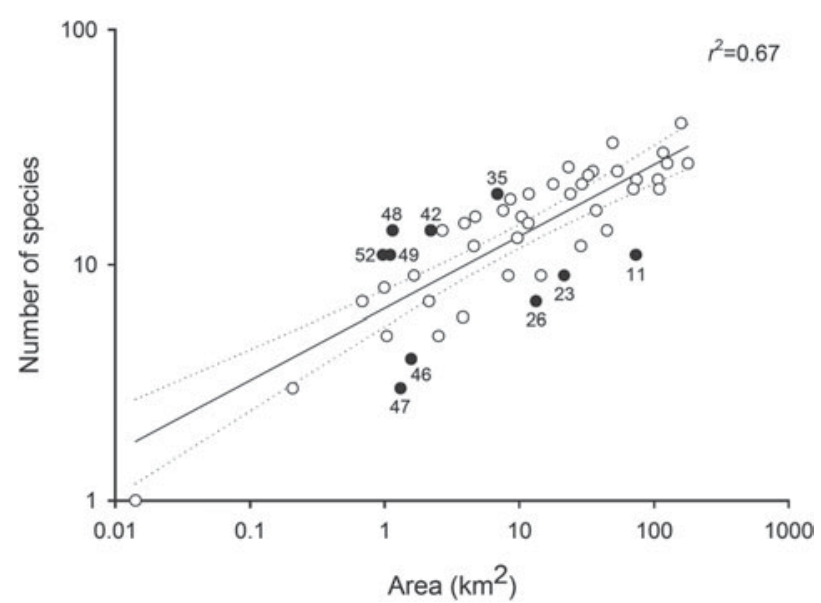

FIG. 2 The relationship between species richness and area for rare plants in the various habitat types in Napa County, California (Fig. 1). Filled, numbered points indicate the habitat types with richness values furthest above or below the value predicted by the model (habitat numbers correspond with Supplementary Table 2).

Redwood (47), Interior Live Oak/Foothill Pine (11), Sclerophyllous Shrubland (26), Riverine, Lacustrine, and Tidal Mudflats (46), and Interior Live Oak (23) had richness values furthest below the values predicted by the model.

Overall, hotspots of rare plant richness occurred in 48 habitat types in Napa County (Supplementary Table 2). The mean area of hotspots in individual habitat types was $0.75 \pm$ SD $1.04 \mathrm{~km}^{2}$. Hotspots overlapped with Douglas-fir/ Ponderosa Pine (16) most frequently, i.e. in $3.99 \mathrm{~km}^{2}$. Hotspots also coincided with $3.39 \mathrm{~km}^{2}$ of California Annual Grasslands (3), $3.06 \mathrm{~km}^{2}$ of Douglas-fir (12), $3.04 \mathrm{~km}^{2}$ of Mixed Manzanita (17), and $2.84 \mathrm{~km}^{2}$ of Leather Oak Xeric Serpentine $(7)$. The richest hotspots, which contained eight rare plant species, coincided with Douglas-fir (12), Knobcone Pine (21), Mixed Manzanita (17), and Rock Outcrops (35). Canyon Live Oak (40) corresponded with a hotspot containing seven rare plant taxa. Of the habitats that were occupied by at least one rare plant, only two types, Coast Redwood (47) and Sugar Pine/Canyon Oak (58), did not correspond to any hotspots.

The percentage of each habitat type in Napa County that was occupied by rare plant hotspots indicated the probability of a hotspot occurring within that particular habitat (Supplementary Table 2). The mean percentage of each habitat type that was occupied by a hotspot was $4.36 \pm$ SD 6.28\%. Ponderosa Pine (53) was occupied by hotspots in the largest proportion of its range, i.e. $28 \%$. Serpentine Barrens (54) and Tanbark Oak (51) were occupied by hotspots in $>20 \%$ of their ranges. Canyon Live Oak (40) and Black Oak (29) were occupied by hotspots in $>10 \%$ of their ranges. Aside from habitat types that did not coincide with any hotspots, those occupied in the lowest percentage of their range $(<0.5 \%)$ included

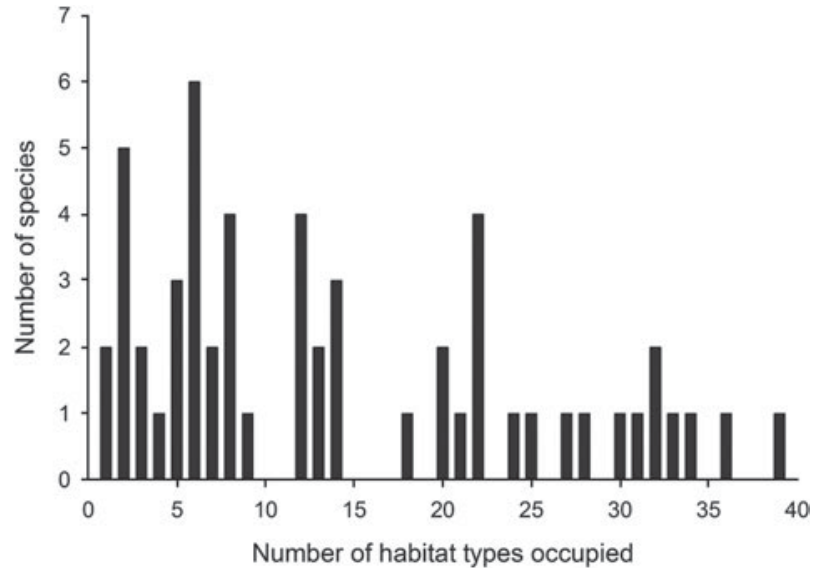

FIG. 3 Frequency histogram showing the number of habitats occupied by individual rare plant species in Napa County, California (Fig. 1).

Riverine, Lacustrine, and Tidal Mudflats (46), WinterRain Sclerophyll Forest (41) and Scrub Interior Live Oak Mesic (15).

A histogram showing the number of habitat types in Napa County occupied by each rare plant species illustrates how restricted they are in terms of habitat specificity (Fig. 3). The mean number of habitats in which a rare plant species occurred was 14.21 \pm SD 10.84 (mode 6). Two species were found only in one type of habitat: Poa napensis Beetle was restricted to Bulrush/Cattail (49) and Castilleja affinis Hook. \& Arn. ssp. neglecta (E.M. Zeile) Chuang \& Heckard was found only in California Annual Grasslands (3). Five species were found only in two types of habitat: Astragalus tener A. Gray var. tener, Balsamorhiza macrolepis Sharp var. macrolepis, Legenere limosa (E. Greene) McVaugh, Limnanthes vinculans Ornd., and Rhynchospora californica Gale. The frequency histogram indicated that rare plants in Napa County had a tendency to occupy a smaller number of habitats as opposed to being distributed more generally. The data were moderately right (positively) skewed $\left(g_{1}=0.66\right)$ and the pattern was highly significant $(t=12.19, \mathrm{P}=0.001)$.

Our calculations of specificity-weighted richness index showed that the maximum possible value for this analysis, i.e. the value if every species occurred in an individual habitat, was 9.39. Although the mean specificity-weighted richness index value for Napa County was 1.10 \pm SD 0.91, several habitat types stood out as having particularly high values (Supplementary Table 2). California Annual Grasslands (3) had the largest value (5.24), followed by Upland Annual Grasslands (3.72). Three other habitat types had values > 2.00: Bulrush/Cattail (49), Coast Live Oak (13) and Valley Oak Riparian Forest (22) had values of 2.24, 2.06 and 2.04, respectively. Five of the habitat types containing rare species had low values. Sugar Pine/Canyon Oak (58) had the lowest value (0.02), followed by Coast Redwood 


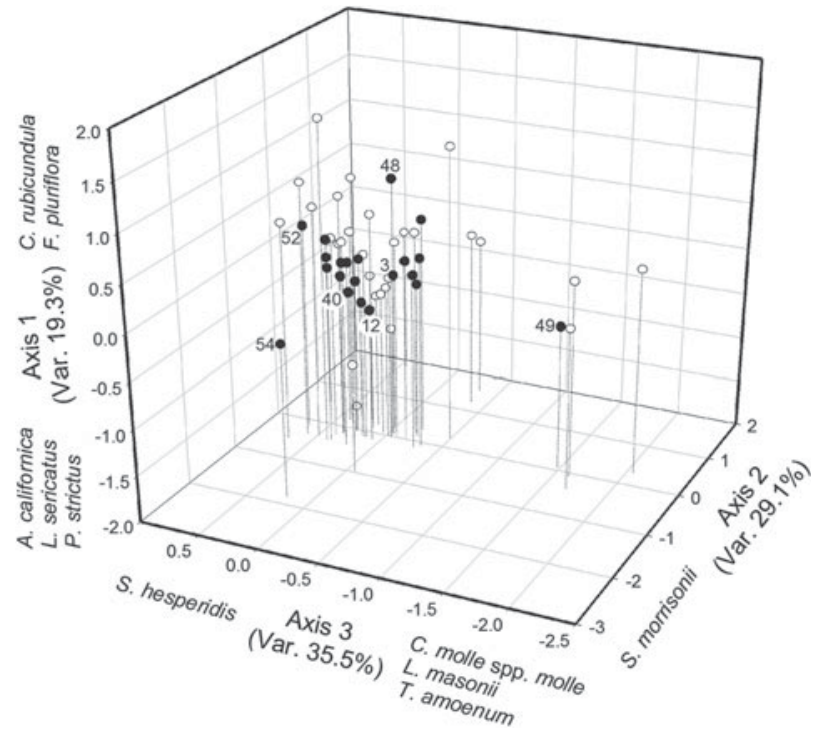

FIG. 4 Non-metric multidimensional scaling ordination analysis of habitat types in Napa County, based on rare species composition. The species listed outside the ordination plot are those with the highest correlation values with the corresponding axis that influence the ordination. The black points indicate the important habitat types in terms of richness and/or presence of hotspots. Collectively, the numbered points represent a series of habitats that would efficiently support rare species in Napa County if conserved.

(47), Serpentine Barrens (54), Riverine, Lacustrine, and Tidal Mudflats (46) and Foothill Pine Chaparral (39), with values of $0.14,0.21,0.25$ and 0.26 , respectively.

A three-dimensional non-metric multidimensional scaling explained $83.9 \%$ of the variation in rare species composition between habitats, with a final stress value of $13.7(\mathrm{P}=0.004$; Fig. 4$)$. Axis 1 accounted for $19.3 \%$ of the variation in the model, axis 2 accounted for $29.1 \%$ and axis 3 accounted for $35.5 \%$. Ten rare species showed the highest correlation values with the ordination, indicating they have the strongest influence on determining the ordination structure. Axis 1 (which accounted for $19.3 \%$ of the variation in the model) was positively correlated with Castilleja rubicundula ssp. rubicundula (Jepson) Chuang \& Heckard $(r=0.62)$ and Fritillaria pluriflora Benth. $(r=0.58)$ but negatively correlated with Amorpha californica Nutt. var. napensis Jepson $(r=0.56)$, Lupinus sericatus Kellogg $(r=0.50)$ and Plagiobothrys strictus (E. Greene) I.M. Johnston $(r=0.51)$. Axis 2 (29.1\% of the variation) was negatively correlated only with Streptanthus morrisonii F.W. Hoffm. $(r=0.50)$. Axis 3 (35.5\% of the variation) was positively correlated with Streptanthus hesperidis Jeps. $(r=0.56)$ but negatively correlated with Chloropyron molle (A. Gray) A. Heller ssp. molle $(r=0.81)$, Lilaeopsis masonii Mathias \& Constance $(r=0.75)$ and Trifolium amoenum E. Greene $(r=0.70)$. Accordingly, these species had the greatest influence on the overall structure of the ordination. Several of the habitats highlighted by the preceding analyses were positioned at the extremities of the ordination axes, indicating large differences in the composition of their rare species communities with respect to the majority. Some habitats were clustered centrally in the model, indicating similarities in the composition of their communities.

Grassland habitats were repeatedly highlighted in this analysis when considering richness, hotspots and specificity-weighted richness. Likewise, several oak-dominated habitat types were highlighted in the context of these measures. Five coniferous habitats and four wetland/ riparian habitats were among the most important in at least one analysis. Three habitats associated with the chaparral ecoregion (Olson et al., 2001) and three serpentine habitats were also highlighted by at least one measure.

\section{Discussion}

The initial stages of the systematic conservation planning framework outlined by Margules \& Pressey (2000) involve compiling data on the locations of rare or threatened species and identifying important habitats as targets for conservation. Our methodology can highlight the most important habitats for rare plant conservation through the use of multiple analyses focused on measures of occupancy, richness, habitat specificity and community composition. Distribution analyses can help to identify habitats that sustain the greatest number of species and richness hotspots (Fiedler et al., 2007; Crain et al., 2011) and habitat specificity measures can help balance conservation efforts between habitats that sustain high levels of diversity and those that harbour species with restricted distributions. Ordination models can also provide guidance, particularly if used in conjunction with the other analyses (Ren et al., 2012). Our study highlights the importance of analysing various characteristics of the habitats of rare plants when identifying conservation targets at local scales.

Our results from Napa County indicate that rare plant species and richness hotspots overlap with a diverse range of habitat types. The significance of habitats similar to those highlighted in Napa County (i.e. grasslands, oak forests, coniferous forests, wetlands, chaparral, serpentines and rock outcrops) has been highlighted in other parts of California and in numerous other locations (Dahl, 1990; Pavlik et al., 1993; Paal, 1998; Lanner, 1999; Maisels et al., 2000; Olson \& Dinerstein, 2002; Lavergne et al., 2004; MEA, 2005; Pykälä et al., 2005; Quinn \& Keeley, 2006; Alexander et al., 2007; Stromberg et al., 2007; Snow, 2010; Duffy \& Kahara, 2011; Garone, 2011; Roche et al., 2012). However, many habitats in the same general categories were less important for rare plants. We were only able to observe these subtle differences by compiling high-resolution habitat (Thorne et al., 2004) and plant distribution data $(\mathrm{CNDDB}, 2006)$ at the initial 
conservation planning stage. Additional studies are needed in other locations to determine if the local associations between rare plants and specific habitat types in Napa County are representative of a broader trend.

By using ordination analyses in conjunction with other analyses to identify conservation targets we demonstrate how planners can protect habitat for the greatest diversity of rare plants more efficiently by focusing on assemblages of important habitat types. The results of ordination analyses can be used to avoid duplicating efforts on habitats that offer diminishing returns. By targeting a series of habitats in Napa County that represent various positions in the ordination model, habitat for the majority of rare plants can be protected locally. For example, by focusing conservation efforts on California Annual Grasslands (3), Douglas-fir (12), Canyon Live Oak (40), Carex spp./Wet Meadow (48), Bulrush/Cattail (49), Brewer's Willow (52) and Serpentine Barrens (54), portions of the realized or potential habitat for $100 \%$ of the species included in this analysis could be protected (Fig. 4). This assemblage includes habitats highlighted for overall diversity, presence of hotspots and specificity-weighted richness, and therefore it is apparent that ordination models are useful guides for increasing efficiency in conservation planning. This habitat assemblage is not the only one that would be appropriate for rare plant conservation; there is flexibility in the choices available. For example, if areas of California Annual Grasslands (3) were unavailable for acquisition, another habitat in a similar position on the ordination model, such as Upland Annual Grasslands (14), could be chosen to ensure that a habitat with a similar rare plant community is represented. In this instance potential habitat for $>75 \%$ of all species would still be included in the conservation plan. The use of ordination models therefore allows planners to take an opportunistic approach during the decision-making process.

This flexibility is an important attribute of our proposed methodology because the availability of important habitats is variable. In Napa County some important habitats, such as California Annual Grasslands (3) and Douglas Fir forests (12), are abundant (Supplementary Table 2; Thorne et al., 2004) and therefore there may be more opportunities to acquire large patches of land in these habitats and to protect larger contiguous patches capable of sustaining numerous species (Roberge \& Angelstam, 2004). These abundant habitats can also be targeted during reintroduction or assisted migration projects (Fiedler et al., 2007), to prepare for shifting conditions as a result of climate change. Conversely, important habitats that are rarer in Napa County, e.g. Bulrush/Cattail marshes (49) and Rock Outcrops (35), can be prioritized for acquisition and restoration projects as opportunities to protect rare plants in these habitats may be limited in other areas. Accordingly, this example highlights how the proposed methods afford local managers the guidance and flexibility necessary to protect conservation targets.

Some caveats regarding the proposed methodology warrant discussion. Although fine-scale habitat and plant distribution maps are available for numerous regions that support important rare plant communities (CDCS, 2000; Helmer et al., 2002; Tozer, 2003; CNRG, 2004; Driese et al., 2004; CNDDB, 2006; Helme \& Desmet, 2006; Panagos et al., 2011), the suitability of our analyses is dependent on the availability of local distribution data. Even though the methods presented could be considered data intensive, they require no more data than other local distribution and habitat models yet they produce more focused and efficient targets then other methods. As with other distribution analyses such as hotspot models, the methodology streamlines conservation efforts by identifying conservation targets for multiple species simultaneously. Our methods provide additional predictive capabilities because results from individual analyses may be applied, albeit cautiously, to other areas with similar species communities and habitats in the event that distribution data are lacking in those areas. Where data are unavailable local agencies are encouraged to begin data collection as a starting point for systematic conservation planning (Margules \& Pressey, 2000), using lower resolution data to identify broader conservation targets that can be refined with subsequent analyses (Wu \& Smeins, 2000). These initial steps are particularly important in regions that have already been highlighted as diversity hotspots at global or national scales (Myers et al., 2000) as multiple-scale habitat analyses are important for focusing conservation efforts (Wu \& Smeins, 200o). Our geographical analysis overlooks abiotic conditions, vegetation structure, microhabitat features, soil type or the presence of mutualistic partners but these parameters can be added to our habitat models (e.g. using GIS and ordination analysis) if necessary. GIS technologies and associated methodologies facilitate such tasks, making comparable studies more feasible (Frederiksen \& Lawesson, 1992; Helmer et al., 2002; Driese et al., 2004). Our results are in accordance with the findings of earlier studies (Press et al., 1996; Sharrock, 2011) that suggest local jurisdictions are empowered for conservation of rare and threatened plant species. In many places legislation facilitates the protection of rare plant communities by local governments and conservation agencies. The methods employed here can be applied in other counties, municipalities and parishes worldwide as researchers continue to collect the comprehensive data sets that are essential for local-level analyses. This process will empower local communities and agencies and remove some of the burden that is often misplaced on federal governments (Press et al., 1996; Sharrock, 2011). It is clear that local conservation efforts can influence biodiversity conservation at greater scales if properly guided. 


\section{Acknowledgements}

Special thanks to our families and friends for their ongoing support. We also thank members of the Biodiversity Research and Education Laboratory at Humboldt State University and of the GIS and Remote Sensing Laboratory at the International Institute of Tropical Forestry. We are grateful for the assistance of Carolina Monmany.

\section{References}

Аввitт, R., Scott, J. \& Wilcove, D. (2000) The geography of vulnerability: incorporating species geography and human development patterns into conservation planning. Biological Conservation, 96, 169-175.

Alexander, E., Coleman, R., Keeler-Wolfe, T. \& Harrison, S. (2007) Serpentine Geoecology of Western North America: Geology, Soils, and Vegetation. Oxford University Press, New York, USA.

BitTMAN, R. (2001) The California natural diversity database: a natural heritage program for rare species and vegetation. Fremontia, 29, 57-62.

Campbell, F. (1991) Endangered plant species shortchanged: increased funding needed. Endangered Species Update, 9, 6.

CDCS (Corporation of the District of Central Saanich) (2000) Municipality of Central Saanich Resource Atlas: Vegetation Mapping. Http://www.centralsaanich.ca/Assets/Central+Saanich/ Publications/CS+Resource+Atlas/Vegetation.pdf?method $=1$ [accessed 13 November 2013].

Ceballos, G. \& Brown, J.H. (1995) Global patterns of mammalian diversity, endemism, and endangerment. Conservation Biology, 9, 559-568.

Chaplin, S., Gerrard, R., Watson, H., Master, L. \& Flack, S. (2000) The geography of imperilment: targeting conservation toward critical biodiversity areas. In Precious Heritage: The Status of Biodiversity in the United States (eds B. Stein, L. Kutner \& J. Adams), pp. 159-199. Oxford University Press, New York, USA.

CNDDb (California Natural Diversity Database) (2006) RareFind v. 3.o.5. California Department of Fish and Game Biogeographic Data Branch, Sacramento, USA.

CNDdB (California Natural Diversity Database) (2013a) Special Vascular Plants, Bryophytes and Lichens List. California Department of Fish and Wildlife, Sacramento, USA.

CNDDb (California Natural Diversity Database) (2013b) State and Federally Listed Endangered, Threatened and Rare Plants of California. California Department of Fish and Game, Sacramento, USA.

CNHP (Colorado Natural Heritage Program) (2011) Colorado Rare Plant Conservation Initiative. Http://www.cnhp.colostate.edu/ teams/botany.asp\#initiative [accessed 14 November 2013].

CNRG (Conservation and Natural Resources Group) (2004) Remnant Vegetation of the Palmerston Municipality. Department of Infrastructure, Planning and Environment, Northern Territory, Australia.

CONABio (Comisión Nacional para el Conocimiento y Uso DE LA Biodiversidad) (2008) Estrategia Mexicana para la Conservación Vegetal: objetivos y metas, pp. 1-36. CONABIO, Mexico City, Mexico.

Connor, E. \& McCoy, E. (2001) Species-area relationships. In Encyclopedia of Biodiversity (ed. S. Levin), pp. 397-411. Academic Press, New York, USA.

Crain, B. \& White, J. (2011) Categorizing locally rare plant taxa for conservation status. Biodiversity and Conservation, 20, 451-463.
Crain, B., White, J. \& Steinberg, S. (2011) Geographic discrepancies between global and local rarity richness patterns and the implications for conservation. Biodiversity and Conservation, 20, 3489-3500.

Crain, B.J. \& White, J.W. (2013) A checklist and floristic summary of the vascular plants of Napa County, California. Phytotaxa, 95, $1-60$.

DAнL, T. (1990) Wetlands Losses in the United States, 1780's to 1980's. U.S. Department of the Interior, Fish and Wildlife Service, Washington, DC, USA.

Dixon, P. \& Cook, R. (1989) Science, planning, and the recovery of endangered plants. Endangered Species Update, 6, 11-14.

Driese, K.L., Reiners, W.A., Lovett, G.M. \& Simkin, S.M. (2004) A vegetation map for the Catskill Park, NY, derived from multitemporal landsat imagery and GIS data. Northeastern Naturalist, $11,421-442$.

Duffy, W. \& Kahara, S. (2011) Wetland ecosystem services in California's central valley and implications for the wetland reserve program. Ecological Applications, 21, S18-S30.

Ellstrand, N. \& Elam, D. (1993) Population genetic consequences of small population size-implications for plant conservation. Annual Review of Ecology and Systematics, 24, 217-242.

Estill, J. \& Cruzan, M. (2001) Phytogeography of rare plant species endemic to the southeastern United States. Castanea, 66, 3-23.

Fiedler, P., Keever, M., Grewell, B. \& Partridge, D. (2007) Rare plants in the Golden Gate Estuary (California): the relationship between scale and understanding. Australian Journal of Botany, 55, 206-220.

Frederiksen, P. \& Lawesson, J.E. (1992) Vegetation types and patterns in Senegal based on multivariate analysis of field and NOAA-AVHRR satellite data. Journal of Vegetation Science, 3 , 535-544.

García, H., Moreno, L.A., Londoño, C. \& Sofrony, C. (2010) Estrategia Nacional para la Conservación de Plantas: actualización de los antecedentes normativos y políticos, y revisión de avances. Instituto de Investigación de Recursos Biológicos Alexander von Humboldt y Red Nacional de Jardines Botánicos, Bogotá, Colombia.

Garone, P. (2011) The Fall and Rise of the Wetlands of California's Great Central Valley. University of California Press, Berkeley, USA.

Gillespie, I. (2005) Habitat characteristics and distribution of Erodium macrophyllum (Geraniaceae). Madroño, 52, 53-59.

Griggs, R. (1940) The ecology of rare plants. Bulletin of the Torrey Botanical Club, 67, 575-594.

Helme, N. \& Desmet, P.G. (2006) A Description of the Endemic Flora and Vegetation of the Kamiesberg Uplands, Namaqualand, South Africa. Report for Critical Ecosystem Partnership Fund (CEPF) Succulent Karoo Ecosystem Planning (SKEP). Http://www.cepf.net/ Documents/helme_desmet.pdf [accessed 14 November 2013].

Helmer, E.H., Ramos, O., Lopez, T., Quiñones, M. \& Diaz, W. (2002) Mapping the forest type and land cover of Puerto Rico, a component of the Caribbean biodiversity hotspot. Caribbean Journal of Science, 38, 165-183.

Kelly, A. \& Goulden, M. (2008) Rapid shifts in plant distribution with recent climate change. Proceedings of the National Academy of Sciences of the United States of America, 105, 11823-11826.

Kelly, J. \& Fletcher, G. (1994) Habitat correlates and distribution of Cordylanthus maritimus (Scrophulariaceae) on Tomales Bay, California. Madroño, 41, 316-327.

Lanner, R. (1999) Conifers of California. Cachuma Press, Los Olivos, USA.

Lavergne, S., Thompson, J., Garnier, E. \& Debussche, M. (2004) The biology and ecology of narrow endemic and widespread plants: a comparative study of trait variation in 20 congeneric pairs. Oikos, 107, 505-518. 
Maisels, F., Cheek, M. \& Wild, C. (2000) Rare plants on Mount Oku summit, Cameroon. Oryx, 34, 136-140.

Major, J. (1963) Checklist of Vascular Plants in Yolo, Sacramento, and Napa Counties, California. University of California Library, Davis, USA.

Margules, C.R. \& Pressey, R.L. (2000) Systematic conservation planning. Nature, 405, 243-253.

Master, L., Faber-Langendoen, D., Bittman, R., Hammerson, G., Heidel, B., Nichols, J. et al. (2009) NatureServe Conservation Status Assessments: Factors for Assessing Extinction Risk. NatureServe, Arlington, USA.

McCune, B. \& MefFord, M. (2002) PC-ORD Multivariate Analysis of Ecological Data. MjM Software, Gleneden Beach, USA.

MEA (Millennium Ecosystem Assessment) (2005) Millennium Ecosystem Assessment Global Assessment Reports. Island Press, Washington, DC, USA.

Myers, N. (2003) Biodiversity hotspots revisited. BioScience, 53, 916-917.

Myers, N., Mittermeier, R.A., Mittermeier, C.G., DA Fonseca, G.A.B. \& Kent, J. (2000) Biodiversity hotspots for conservation priorities. Nature, 403, 853-858.

Neilson, J. \& McQuaid, D. (1981) Flora of the Mayacamas Mountains. Ecoview Environmental Consultants, Napa, USA.

Olson, D. \& Dinerstein, E. (2002) The global 200: priority ecoregions for global conservation. Annals of the Missouri Botanical Garden, 89, 199-224.

Olson, D., Dinerstein, E., Wikramanayake, E., Burgess, N., Powell, G., Underwood, E. et al. (2001) Terrestrial ecoregions of the world: a new map of life on earth. BioScience, 51, 933-938.

PAAL, J. (1998) Rare and threatened plant communities of Estonia. Biodiversity and Conservation, 7, 1027-1049.

Panagos, P., Jones, A., Bosco, C. \& Senthil-Kumar, P.S. (2011) European digital archive on soil maps (EuDASM): preserving important soil data for public free access. International Journal of Digital Earth, 4, 434-443.

PARISI, M. (ed.) (2003) Atlas of the Biodiversity of California. California Department of Fish and Game, Sacramento, USA.

Pavlik, B., Muick, P. \& Johnson, S. (1993) Oaks of California. Cachuma Press, Los Olivos, USA.

Peterson, A. (2006) Uses and requirements of ecological niche models and related distributional models. Biodiversity Informatics, 3, 59-72.

Planta Europa (2003) A Joint Council of Europe and Planta Europa European Plant Conservation Strategy. Https://wcd.coe.int/com. instranet.InstraServlet?command $=$ com.instranet.CmdBlobGet\&In stranetImage $=1336624 \&$ SecMode $=1 \&$ DocId $=1462576 \&$ Usage $=2$ [accessed 14 November 2013].

Pomeroy, D. (1993) Centers of high biodiversity in Africa. Conservation Biology, 7, 901-907.

Press, D., Doak, D. \& S Teinberg, P. (1996) The role of local government in conservation of rare species. Conservation Biology, $10,1538-1548$.

Pykälä, J., Luoto, M., Heikrinen, R. \& Kontula, T. (2005) Plant species richness and persistence of rare plants in abandoned seminatural grasslands in northern Europe. Basic and Applied Ecology, 6, 25-33.

Quinn, R. \& Keeley, S. (2006) Introduction to California Chaparral. University of California Press, Berkeley, USA.

Rabinowitz, D. (1981) Seven forms of rarity. In The Biological Aspects of Rare Plant Conservation (ed. H. Synge), pp. 205-217. John Wiley \& Sons, Chichester, UK.

Ren, H., ZenG, S., Li, L., Zhang, Q., YAnG, L., WANG, J. et al. (2012) Reintroduction of Tigridiopalma magnifica, a rare and Critically Endangered herb endemic to China. Oryx, 46, 391-398.
Roberge, J. \& Angelstam, A. (2004) Usefulness of the umbrella species concept as a conservation tool. Conservation Biology, 18 , $76-85$.

Roche, L., Rice, K. \& Tate, K. (2012) Oak conservation maintains native grass stands in an oak woodland-annual grassland system. Biodiversity and Conservation, 21, 2555-2568.

Safford, H., Viers, J. \& Harrison, S. (2005) Serpentine endemism in the California flora: a database of serpentine affinity. Madroño, 52, $222-257$.

Sharrock, S. (2011) Global Strategy for Plant Conservation: A Guide to the GSPC. All the Targets, Objectives and Facts. Botanic Gardens Conservation International, Richmond, UK.

Skinner, M. \& PAVlik, B. (1994) Inventory of Rare and Endangered Vascular Plants of California. California Native Plant Society, Sacramento, USA.

SNOw, L. (2010) State of the State's Wetlands Report: Ten Years of Challenges and Progress. Http://dev.californiawetlands.net/static/ documents/Final_SOSW_Report_09232010.pdf [accessed 14 November 2013].

Sokal, R. \& Rohlf, J. (2012) Biometry. W.H. Freeman, New York, USA.

Stebirins, G. \& Major, J. (1965) Endemism and speciation in the California flora. Ecological Monographs, 35, 1-35.

Stromberg, M., Corbin, J. \& D’Antonio, C. (eds) (2007) California Grasslands: Ecology and Management. University of California Press, Berkeley, USA.

Thorne, J., Kennedy, J., Quinn, J., McCoy, M., Keeler-Wolf, T. \& MenKe, J. (2004) A vegetation map of Napa County using the Manual of California Vegetation classification and its comparison to other digital vegetation maps. Madroño, 51, 343-363.

Tozer, M. (2003) The native vegetation of the Cumberland Plain, western Sydney: systematic classification and field identification of communities. Cunninghamia, 8, 1-75.

VEECH, J. (2000) Choice of species-area function affects identification of hotspots. Conservation Biology, 14, 140-147.

Viers, J., Thorne, J. \& Quinn, J. (2006) CalJep: a spatial distribution database of Calflora and Jepson plant species. San Francisco Estuary \& Watershed Science, 4, 1-18.

Wiser, S., Peet, R. \& White, P. (1998) Prediction of rare-plant occurrence: a southern Appalachian example. Ecological Applications, 8, 909-920.

Wu, X. \& Smeins, F.E. (200o) Multiple-scale habitat modeling approach for rare plant conservation. Landscape and Urban Planning, 51, 11-28.

\section{Biographical sketches}

Benjamin J. Crain's primary research interests include biogeography, conservation biology, ecology of threatened species, and population viability analyses. Much of his research involves the use of geographical information systems and matrix models to analyse rare species in biodiversity hotspots. ANA MARÍA SÁNCHEZ-CUERVo is a conservation biologist whose research involves the use of geographical information systems, spatially explicit models, spatial analysis and multivariate statistics to understand patterns, causes and consequences of global environmental change. Jeffrey W. White's primary research interests include plant biogeography, science education and scientific film-making. Steven J. Steinberg specializes in geographical information systems, data management systems, remote sensing, spatial analysis, natural resources, and image processing. $\mathrm{He}$ has researched the application of spatial analysis and web-based systems for modelling and visualization of spatial data in both human and natural environments. 